\title{
Business Law Literacy and Motivation Force for Quality of Knowledge, Talent and Ability in Support for Self-Development of Youth Macedonian
}

\author{
Ljupcho Naumovski \\ PhD, PVPU "Euro College" Done Bozinov 41,1300 Kumanovo, North Macedonia, \\ https://orcid.org/0000-0002-2162-8740
}

\begin{abstract}
The world is really in a fast-changing process with the emergence of new technologies and new products, and the market makes it in a state of constant motion. All of this results in each individual's motivation, knowledge and selfdevelopment to grow every day. But every day the amount of information is growing. Therefore, we are often in a dilemma of why the same people in the same or almost identical conditions achieve different successes, so at the same time, we turn to the concept of motivation, knowledge, ability, confident that the difference in people's success can be explained with this. Discussing this problem is impossible without considering the role of manifestation and development of motivation for knowledge and skills acquisition. Knowledge is one of the most important activities of man. At all times, people try to get to know the world around them, society, and even themselves. Abilities are characteristics of temperament properties, which are reflected in the activity of regulatory systems, which can be expressed in an individual approach to a person in the process of performing his or her professional activities, in the process of communication, and the correction of individual behaviour.
\end{abstract}

Motivation is one of the most important drivers of the economic activity of the personnel and organization management system, with the main aim of creating the conditions for the motivation of the work team. In this case, a wide range of questions must be answered: What motivates a person's economic activity? What are the motives for consumer behaviour in the commodity market? What drives a person to buy or sell stocks? What motivates them to desire to change jobs or professions? What attracts (deters) the new position offered to him?

Keywords — Motivation; Knowledge; Abilities; Talent; Skills.

\section{Introduction}

Every nation is proud of the results of its business activities. While every nation and its individual representatives are proud of their participation in the implementation of any particular business idea. Entrepreneurship as a motor of social relations contributes to the enrichment of the material and spiritual potential of society, but therefore, creates realistic conditions for the practical realization of the knowledge and abilities of each individual, so that is a bearer of national unity and national pride. In this regard, society has a great need to prepare young people capable of active self-development, creative solution to non-standard situations and realization of their unique, inexplicable human personality. It becomes obvious that the proactive, motivated, Knowledgeable and creatively capable and thinking individuals form the head of society to solve urgent problems. Therefore, the priority task is to create the most favourable conditions conducive to active self-development of the individual. The formulation of life strategies for personality development is now gaining special significance, as the transformations that take place in different spheres of our society influence the values that determine the choice of young ways to build our own lives.
West of imposing authentic living standards, through overrated, unjustified claims, is becoming increasingly entrenched in the minds of young people. The inability to implement them often leads to disappointment and substitution of moral judg ments and, of course, affects the selection of young people for social success criteria and their attitude towards education. The research of young people in North Macedonia only confirms the modern model of life success: the greatest achievement is considered the maximum independence from society. Typical texts on the question "What needs to be done now to be successful in to morro w's life?" answers "you need to have a good education for acquiring knowledge, full motivation and real ability to get a well-paid job so you do not depend from anyone". The public life and politics are at the bottom of their list of interests and activities. Analysing and explaining their responses, the youth highlighted the instability, uncertainty, unpredictability and unpredictability of northern Macedonian society and, in their view, "eliminates the implementation of personal plans through their self-development". The aspirations of the modern man are sometimes built not on a true belief in personal abilities, but on a desire to triu mph over so meone, including my own idealized self. Most people who complain about the current government, which they say does not provide them with a "good" life, do not even think

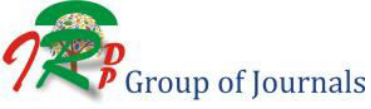


that the absence of a "good" government is a result of people's distrust of their abilities. Most relevant, in my personal opinion, self-development through life strategy is the scale of responsibility, if any, ability, level of meaning, reflected through the system of values and human relationships.

\section{Theoretical Basis}

High levels of uncertainty in life, unclear prospects for social development of society, material difficulties lead Macedonian young people to look with great anxiety and fear to morrow. The general theoretical basis of our study is made of works devoted to the self-realization of pers onality in L. Kulikova and representatives of her science school: N. Grigorieva, T. Klimenko, L. Lazareva, O. Lapicki, E. Fedotova and others. Personality development in the works of O. Abdulina, S. Archangelski, I. Isaeva, N. Kuzmina, V. Serikov. In the professional literature, the question of support for personal self-development, ie in the works of $\mathrm{O}$. Gazman, L. Kulikova, N. Grigorieva, T. Klimenko, L. Lazareva, O. Lapicki, E. Fedotova, et al., Who in their scientific studies consider different aspects of this kind of activity. However, unified views on the nature of this phenomenon have not yet been developed, making it necessary to continue the theoretical and methodological interpretation of existing and new scientific approaches and psychological theories aimed at improving the professional support of young people's personal development. All this has led to the importance of the research topic. But in professional, scientific literature, contradictions are noticeable: between the demands for self-development and the forms of training and knowledge acquired by young people; a full-fledged creative person and a lack of support for personal self-development; between societies's need for young people capable of creative solutions to non-standard situations and lack of experience in youth practice.

Despite the numerous scientific studies devoted to the problems of personality development, intellectual and creative talent, the reform of the educational process, many thematic issues require a more detailed interpretation. The expediency of scientific research is motivated, moreover, by the increasing demands of modern society for the quality of future specialists in various industries, the increasing competition in the labour market, to restore the nation's most powerful intellectual and creative resource.

To effectively solve the problem, it is necessary to synthesize, based on the northern Macedonian educational traditions, taking into account the features of the northern Macedonian mentality and culture, on the achievements in the field of education of foreign countries and the extrapolation of the acquired knowledge in the field of North Macedonian reality. Professional self-determination is self-awareness of professional activity, as a result of which certain professional choices are made; the process of independent and informed discovery of the meanings of professional choice and all life activities in a particular cultural-historical (socio-economic) situation, as well as finding meaning in the process of self-determination. The purpose of this paper is motivation, development of intellectual creative abilities of young people i.e. personal, social and cognitive characteristics on the choice of the direction of youth professional activity and to analyse the relation of such phenomena as motivation, ability, selfdevelopment.

The individual style of, the individual is realized on activity methods that are reluctant or no visible personal subjective effort (spontaneous) to be encouraged in an objective environment based on the complex topological properties of the human system that every person has. If these do not provide all the normal, adjustable effects and if necessary, another set of activities appears that develop in some more or less long searches (conscious or spontaneous). Example, inertia, is not a tendency to move away from the work already started but is an activity of/for effective balancing with the environment, to bring the activity to an end. The subject of the paper is the content, forms and methods for developing young people's intellectual creativity. Research methods in the paper, in accordance with the purpose and objectives, theoretical analysis and synthesis of pedagogical, psychological, methodological literature, modelling methods, analysis, synthesis, mass practice generalization and advanced domestic and foreign experience have been carried out.

\section{Motivation}

Motivation (from lat. Movere - the impulse to action) is the process of inducing a person to a certain type of activity using intrapersonal and external factors. The main characteristic of man, which distinguishes him from the animal world, is that he is a social being who performs activities, i.e. the process of appropriate changes and transformations of the surrounding reality in the name of meeting our needs and interests: economic, political, cultural, etc. The fact is (and it is undeniable) why, a person is engaged in productive activities and what are the causes and factors that trigger a certain type of economic behaviour, as and for the pursuit of economic activity, and in certain social circumstances and forms? Therefore, science, among its important tasks, reveals the drivers of economic activity and its motivation.

In this case, it must answer a wide range of questions. What motivates a person's economic activity? What are the motives for consumer behaviour in the commodity market? What drives a person to buy or sell stocks? What motivates them to desire to change jobs or professions? What attracts (deters) the new position offered to him? What are you

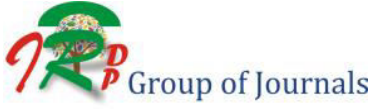


hoping for, investing in a particular industry (for example, oil production)? What does he value most in the work of his employees? What is he prepared to fight with all his might? The list of such questions can be easily extended, but they are all united by something in common. This common only constitutes this complex, multi-layered socio-psychological process called motivation. Even an incomplete list of questions related to activity motivation indicates that the process we are studying has a complex socio-psychological structure, which includes the main components of the need, the goal set, the actions taken by the individual (group), sufficient or insufficient to achieve the goal. This motivational structure is shown in Figure 1.

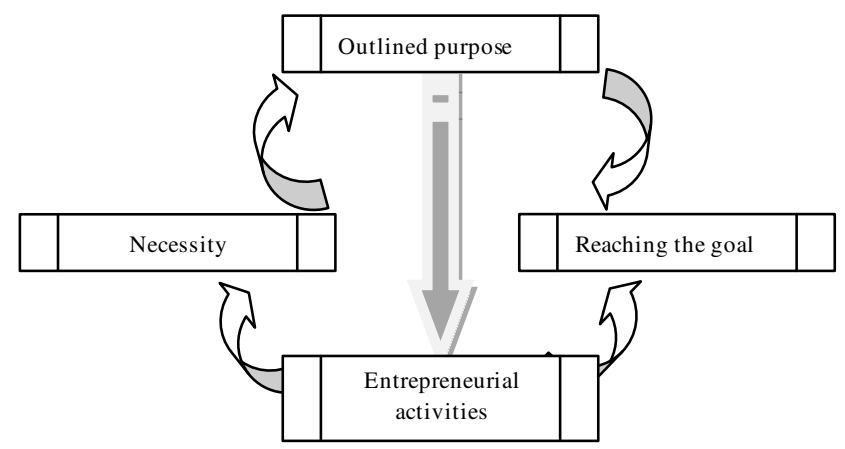

Fig.1: Motivational Structure

For the first time, the term "motivation" was introduced by the extraordinary German philosopher A. Schopenhauer in the circle of scientific and philosophical communication in the article "Four principles of sufficiency reason" to explain the reasons for human behaviour. Afterwards, he firmly entered the psychological, sociological, economic literature and in contemporary usage expresses a set of factors that cause human activity and determine the course of his behaviour and activity.

According to contemporary views, motivation is the process of forming and implementing an activity's motives for the needs and goals of the individual, his or her interests, beliefs, conditions of activity, characteristics of relationships and interactions with the people around him, the situation in which such an interaction occurs and etc. A motive is a complex socio-psychological phenomenon that encourages a person to become conscious, active activities and activities and serves as a reason (basis) for them. More than fifty motivation theories have been developed in world science. Together with psychologists W. James, A. Maslow, J. Godfroix, H. Heckhausen, G. Opport, A. Leontiev, E.Ilin, P. Jacobson, economists F. Taylor, J. Schumpeter, A. Marshall, D. Gelbreath, P. Drucker, sociologists Mayo, F. Herzberg, made a significant contribution to the development of problems with motivation, healthy reason and many others.

\subsection{Characteristics of the B usiness Motivation Theory - Developed by Joseph Schumpeter}

Prominent Austrian and American economist and social theorist Joseph Schumpeter, who combined economic analysis with sociological analys is in his studies, attached great importance to clarifying the motivational structure of entrepreneurial activities. In his well-known work Theory of Economic Development, he has convincingly proved that the entrepreneur acts as the main driving force behind the market economy. An ordinary entrepreneur, with his own hands and head creating a market economy, he says, "works without knowing peace, because it cannot be otherwise, the purpose of his life is not to enjoy what he has achieved. The motto of our kind entrepreneur is even more so.

The motives of his behaviour correspond to this motto (Schumpeter I, 1982, Theory of Economics developed, p.192). What is the motivation for deliberate, restless entrepreneurial activity? Answering this question, $\mathrm{J}$. Schumpeter identifies three main sets of motivations for entrepreneurial activity. "First of all," he writes, "it is the dream and the will to establish a private empire and - in most cases, though not always, one's dynasty. His empire gives him space and a sense of power, but this is the first approximation to a state of total domination, a state familiar with this world and which is particularly attractive only to those people who otherwise cannot attain a position in society"( Schumpeter J, 1982, Theory of Economics developed. p.193). This group of motives includes freedom, conditions for personality development, a desire to dominate the surrounding people, and so on. The second group of motives for entrepreneurial activity, accord ing to $\mathrm{J}$ Schumpeter is "linked to the will to win". This includes, on the one hand, the desire for struggle and victory in it, and on the other, the desire for success. The profit margin here is an indicator of success and a symbol of victory. Therefore, economic activity is considered by a typical entrepreneur to be a specific sport: a kind of financial race or, more precisely, a boxing match. Finally, the third set of motives that underpin entrepreneurial activities, Schumpeter argues, is related to the joy of creativity, which is manifested in other cases but only here becomes a decisive moment of behaviour. As for the motives of behaviour who belong to the first of the aforementioned motivation groups, then, according to J. Schumpeter, "Private ownership formed as a result of entrepreneurial activity is an important indicator of the effectiveness of this activity". In the other two motivational structures, it is not so much about ownership but about methods that measure the 'success' or 'victory' of a capitalist society, that the business that gives its creator joy is realized and justifies itself'(Schumpeter J, 1982, Theory of Economics developed. p.194). 


\subsection{Essence of the Integrative Model of Consumer Behavior Motivation - Proposed by J. F. Angell, R.D. Black well, P. Miniard}

Along with the already described motivators, a wide range of consumer behavior motivation was covered in his fundamental work "Consumer Behavior" by three American doctors of philosophy: James F. Angell, Roger D. Blackwell, Paul Miniard. They begin the presentation of this spectrum with the determining motivating role of the conscious need, and emphasize that "both rational (utilitarian) and emotional reasons are the basis of consumer motivation" (Angel J.F., Blackwell R.D., Miniard P.U., 1999, Consumer behaviour, p.331). They also indicate a significant role of the consumer's interest in motivation, i.e. his predisposition to her, the influence of the emotional state, from which the well-known marketing principle follows: "It is easier to win the consumer if you create a good mood for him." The unity and stability of motivational models that guide the consumer in their behavior is very important.

A significant influence on him also has a desire for self-esteem and self-assertion in public opinion. Often, the trigger for this or that, sometimes extravagant consumer act is the imagination of the buyer. Of course, self-control has a powerful influence both in pushing to one or another consumer behavior and in deterring it. Self-control can manifest itself in three forms: 1) concern about the social relevance of behavior; 2) attention to social differences as a way of determining the appropriate self-expression; 3) the ability to "submit" oneself in different ways and express their feelings depending on the situation. One of the most powerful motivators of consumer behavior is knowledge. It is it that most often allows the consumer to make a choice of a product, to determine the most acceptable set of goods and services that need to be purchased, as well as those things that should be discarded. Also a very important stimulant of certain consumer actions and even habits is directed (in the family, school, in the work collective, etc.) or random (in the store, on the market, in the exchange office) consumer education.

In consumer education, the role of life experience, which consumers often turn to when making a purchase, is also very significant. Recently, in North Macedonian, the motivating ability of advertising in its various forms television, newspaper, radio wave, poster, etc., has sharply increased. If the impact of personal communication sources when one person receives information from another (friend, co-worker, seller, etc.) is limited solely by the person transmitting the message, then the impact of impersonal advertising messages (via radio, television, press, etc.) is more large-scale, diverse and complex. Finally, one cannot ignore the motivating influence on consumer behavior of the understandable desire of the latter to gain the approval of others. It is well known that when a person buys wine for his own consumption, he rarely (with the exception of rich people) chooses expensive and prestigious brands of wine, but if he makes a drink for reception, considerations of prestige, approval or disapproval of others, encourage him to buy more expensive wines stamps.

The whole set of characterized factors of consumer motivation can be represented graphically in the form of a figure 2 .

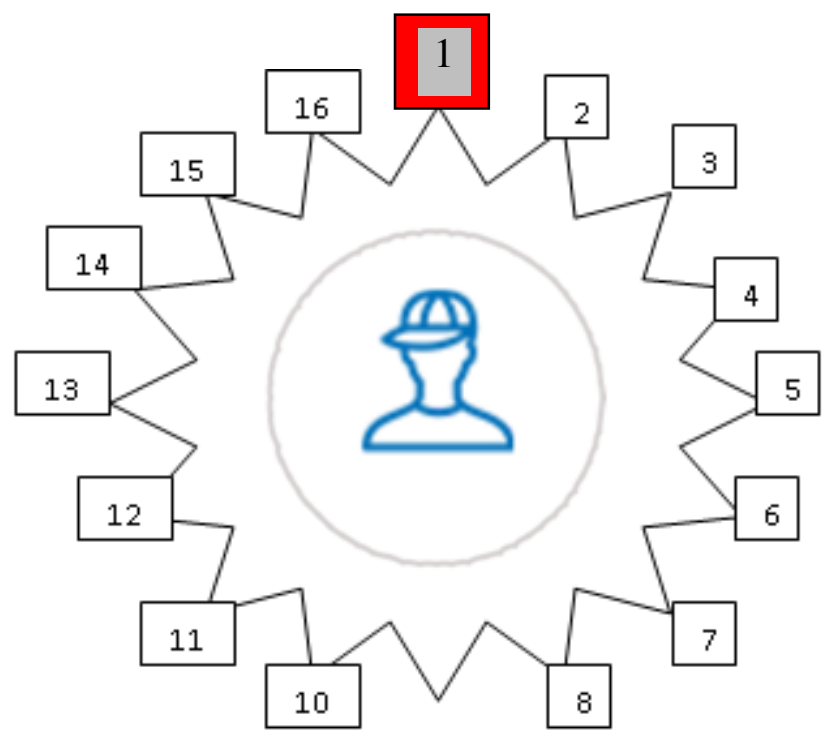

Fig.2: Consumer Motivation

From the figure, 1. The desire to increase needs. 2. Budget consumption restrictions. 3. The life cycle of consumption. 4. The effect of income. 5. The effect of substitution. 6. Maximizing utility. 7. Budget containment. 8. The limiting effect of prices. 9. Aware need. 10. Consumer interest. 11. The unity and stability of the motivational model. 12. Fantasy of the buyer. 13. Knowledge. 14. Consumer education. 15. Motivational abilities of advertising. 16. Approval (disapproval) of others

\section{Education/Knowledge and Technology Race}

As technology advances, so does the need to educate people on how to use them, and the education system must adapt to continue? In this sense, technology and education knowledge gained compete (C. D. Goldin and L. F Katz, 2009, The Race between Education and Technology). Unfortunately, at a time when education and thus and knowledge lags behind technological advances, people, and especially young people, are not qualified to work and are not as productive and effective as they can be. In addition, economic inequality is growing - because those who have

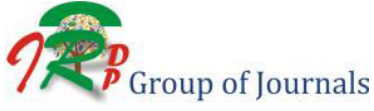


the opportunity to receive an excellent education, and thus knowledge have more prospects for success, and those who cannot provide highly effective education, have no hope of improving their own financial standing. Thus, both individuals and society as a whole suffer from personal stress and social unrest. The term "knowledge" is usually used in three main senses: a) abilities, skills that are based on the knowledge of how to do something, to implement; b) any cognitively significant (in particular, adequate) information; c) a special cognitive unit, an epistemological form of a person's relationship to reality, existing along with and in conjunction with "one's other" - with a practical attitude. The second and third aspects are the subject of consideration of epistemology (theory of knowledge) and epistemology - the theory of scientific knowledge. Speaking of forms of knowledge, one cannot ignore the fairly well-known (especially in modern Western epistemology) concept of personal knowledge developed by the British scientist M. Polani. He started from the fact that knowledge is an active understanding of familiar things, an action that requires special arts and special tools. Because science is made by humans, the knowledge gained in the process of scientific activity (such as this process) cannot be destroyed. And this means that people (or more precisely scientists) with all their interests, preferences, goals, etc. They cannot be separated from the knowledge they produce or mechanically replaced by other people.

According to Polani, personal knowledge necessarily involves intellectual teaching. It captures not only the known reality, but also the cognitive personality itself, its interested (and not indifferent) attitude towards knowledge, a personal approach to its interpretation and use, its own interpretation in the context of specific, purely indiv idual, variables and, as a rule, an uncontrolled association. Polani advocates that man has two types of knowledge: explicit, articulated, expressed in concepts, judgments, theories and other forms of rational thinking and implicit, implicit, not fully reflective layers of human experience. Implicit knowledge is not articulated in language and is embodied in body skills, perception patterns, practical mastery. It does not allow for full explanation and presentation in textbooks, but it is transmitted "hand in hand" in communication and personal contacts of researchers. At the moment, there is growing interest in the problem of the irrational, that is, beyond the reach of the mind and cannot be understood by means of known rational means, but at the same time the conviction that the presence of irrational layers in the human spirit causes that depth from which all new meanings, ideas, creations appear. The mutual transition of the rational and the irrational is one of the fundamental foundations of the process of cognition. However, the importance of irrational factors should not be overstated, such as that is what adherents of irrationalism do.

\section{Components and Development of Professional Self- De velopment}

A person's professional self-development is ontogenetically related to the main types of his or her activity corresponding to adulthood, so E. Klimov points to three periods in which each of them identifies and characterizes the stages of development of professional formation, ie professional self-determination through a system of socially significant value ideas, ideals (mental patterns for building life, activity, career path), within active and effective assimilation of the system of proper relationships with peers and the elderly, active introspection and correlation of one's personality with the adult world, trying to realistically plan one's future. At that time, the information bases of the moral, social and, consequently, professional orientation of the person is being formed especially intensively and actively. This period is characterized by active attempts at selfimprovement: self-education, self-organization, the desire to prepare for the future. The ability of awareness, control of thinking operations and their voluntary management is developing intensively. The optics phase ends with the design of a specific psychic neoplasm specific to the structure of the subject of activity (in his selfconsciousness) - a realistic idea of a particular "reference" professional community in which he engages himself in the future. E. Klimov, V. Shebisheva, believes that professional self-determination is an essential aspect of a person's general self-development.

The ability for professional self-determination, according to S. Fukuyama is defined as the ability to make a conscious choice of profession. The following criteria and indicators of student self-determination for professional self-determination are listed in the specialized literature: - cognitive (knowledge of the professions, their professional qualities, ways of professional selfdetermination); -motivational-demand (positive attitude towards a professional career, appropriate attitude towards self as the subject of professional self-determination, creative attitude towards activities that promote professional self-determination, assessments for assessing one's activities in preparation for professional selfdetermination); - activity-practical (opportunity for selfrealization, the test of strength, orientation towards creativity, opportunity for expert advice, the opportunity for self-improvement).

T. Kudriavetsev, A. Suhareva and other researchers on problems with professional self-determination believe that in the vocational education process students need to "basically complete their professional self-determination, that is, to form a connection with themselves regarding the subject of their profes sional activity".

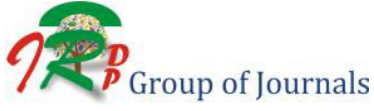




\section{The Concept of Abilities}

The concept - ability in W. Dahl, "capable" is defined as "suitable for anything or inclined, proficient, manual, convenient, convenient".

A capable person is resourceful, weird, capable of adapting and adapts, i.e. manages, organizes business. In fact, it is understood as qualified, but the concept of "skill" is not in the dictionary. Thus, the concept of "capable" is defined by the relation of success to activity. Speaking of ability, one emphasizes one's ability to do something and one speaks of talent (gift), the innate character of this quality (ability) of a person. A general approach, the capability is any manifestation of a person's capabilities (starting premise: the person is capable, can perform any activity). How to develop people's capabilities more effectively and effectively, including their knowledge and skills? This point of view has long roots. For example, according to $\mathrm{K}$. Ushinski the mind is nothing but a wellorganized system of knowledge. As a result, the problem of abilities takes on a psychological and pedagogical connotation. It turns out that all people are capable, everyone can do everything. So in the book of V. Druzinin "The Psychology of General Abilities" this tradition finds its continuation, as general abilities are understood as intelligence, learning ability, creativity. It is not down to what level a person can achieve a certain type of activity, but how much he/she will sweat to achieve the same result as capable people. Hence the capability formula is the formula of abilities F.1:

$$
\text { Ability }=\frac{\text { Success or productivity }}{\text { Labour or price }}
$$

\section{F.1: Formula of Abilities}

With an individualized (differentiated) approach, on the contrary, are highlighted differences between people in/with their abilities. Teplov B., as a follower, does not include knowledge and skills in his abilities and has good reasons for this, which can be found in the biographies of many talented people. The general approach loses the specificity of the concept of "capability", becomes optional (probably talking about opportunity, quality, even skill), and the problem itself is "blurred", from an aspect of human learning and development. Having the abilities means having organic, hereditary fixed preconditions for their development in the form of inclinations? People from birth are endowed with various inclinations. Diversity of humans is the innate anatomical, physiological and functional characteristics of the personal neuro-brain apparatus. Natural differences between people are not differences in finished abilities, namely in inclinations. There is a big difference between inclinations and abilities, between one and the other, it's all the way to personality development. Acts are more valuable; they can be developed in different directions. Inclined are just opportunities, and prerequisites for skills development, but however they do not guarantee, don't do it predetermine the layout and development of certain abilities. Appearing are based on inclinations, abilities are developed in the process and under the impact of activities for which require certain abilities of a person. Outside the activity, anyone ability cannot be developed. Neither one person, no matter what kind tendencies they possess, can't become a talented mathematician, musician or artist without engaging in much and persistently relevant activity. We must add that on the same inclinations; can to develop unequal abilities, in addition from the nature and require ments of activity in which everything engages one person, how and the living conditions and especially the educational process.

Therefore, one of the modern approaches to study on abilities is a close connection to abilities with the theory of activity and personality. Theory of activity her explains their appearance, and the theory of personality - place in the structure of personality. According to that, capabilities are defined as properties (or set of properties) of an individual affecting the effectiveness of activities (Ilyin E.P., 2004, Psychology of individual differences, p. 701). Teplov B.M. (Teplov B.M., 1985, Selected works: In 2 volumes of $M$,) identified three signs of ability, which is the basis for the definition most commonly used by specialists: 1 . abilities are individual psychological characteristics that everything differs from one person from another; 2.only those features what are relevant for the success of one or more activities; 3. abilities cannot reduce of knowledge, skills and abilities what already there are developed person, though they got her to determine the ease and speed of their acquisition. Thus, abilities are individual psychological characteristics that determine the success of an activity or a series of activities, they cannot be reduced to knowledge, skills, but they determine the ease and speed of learning new modes and methods of activity.

\subsection{Structure and Classification of Abilities}

S.L. Rubinstein (Rubinstein S.L., 1999, Fundamentals of General Psychology, p.720) defined composition, the structure of ability: "The composition of each ability what makes man capable to perform a particular activity always involves some operations or modes of action through which this activity is carried out. No single ability is a real, real ability until it has organically incorporated a system of relevant socially developed operations; but the essence of ability is not assimilated, not automated work, but those mental processes that govern these operations". Thus, S.L. Rubinstein identifies two main components of the capability structure: 1)"operational" - these are the modes 
of operation through which the activity is performed; and 2)

"core" - the mental processes that regulate operations, such as the qualities of the processes of analys is and synthesis.

Abilities can be classified as follows: 1. Natural. In essence, they are biologically determined, linked to innate tendencies, formed on the basis of them in the presence of basic life experience through learning mechanis ms - such as conditioned reflexive connections. 2 . Specifically human. They have a socio-historical background and provide life and development in a social environment.

They are, in turn, divided into: 1. General: they determine a person's success in a wide range of activities and communications (mental abilities, developed memory and speech, accuracy and subtlety of hand movements, etc.) and in particular: they are related to a person's success in certain types of activities and communications that require a special kind of preparation - mathematical, technical, literary and linguistic, artistic, sports and other abilities. The presence of common abilities in one person does not prevent the development of the special and vice versa. Often, general and special abilities coexist, complement and enrich one another. 2) Theoretical and practical abilities are distinguished by the former predisposing the tendency of the person to abstract logical thinking and the latter to specific, practical activities. Such abilities, in contrast to the general and the special, are often not combined with one another, fulfilling only among gifted, versatile talented people. 3) Educational and creative abilities differ from one another in that the former determines the success of training and education, the assimilation by the person of knowledge, skills, the formation of personality traits, while the latter determines the creation of objects of material and spiritual culture, producing new ideas, discoveries and inventions. The highest degree of a person's creative manifestations is called a genius, and the highest degree of a person's ability in a particular activity (communication) is called talent. 4) Ability to communicate, interact with people, as well as subject activity or subjective-cognitive abilities - most socially determined. They are related to people's interaction with nature, technology, iconic information, artistic images, etc.

\section{Talent}

\subsection{Basic Concepts}

Talent is inherent in the birth of certain abilities that are revealed by the acquisition of skill and experience. The word "talent" comes from a measure of "talent" weights. In the New Testament, there is a parable of three slaves to whom the owner gave a coin called "talent". One buried his talent in the ground, the other exchanged it, and the third increased it. Hence, the three expressions: buried, exchanged and multiplied, respectively, developed his talent. From the Bible, the word "talent" has spread figuratively: as a gift from God, the ability to create something new without neglecting it. Modern scientists distinguish certain types of talents that humans possess to one degree or another.

The most dignified stage of abilities is called talent. As well as abilities, talent is only an opportunity to acquire great skill and significant success in creativity. Awakening talents is socially determined, and which talents will receive full development under the most favourable conditions depends on the needs of the era and the characteristics of the specific tasks that the state faces. For example, during the wars, the birth of military talents can be observed, and in peace - engineering, architectural. Talent is such a complex combination of one's mental qualities that it cannot be determined by any single ability. Instead, on the contrary, absence or, to be more precise, the weak development of every even important ability, as psychological studies attest, can be successfully offset by the intense development of other abilities that are part of a complex ensemble of talented qualities. A genius is the highest level of ability because it creates the opportunity for a person to achieve the epoch-making results of society itself, in the development of science and culture. There is no such set of properties that would determine a genius.

\subsection{Classification of Talents}

In psychology, it is customary to distinguish eight types of talents: Verbal - linguistic. He is responsible for the ability to write and read, typical of journalists, writers and lawyers. Digit - Digital is typical of mathematicians, programmers, or people who work with nu mbers every day. Auditory is specific for musicians, linguists and linguists. Physical is characteristic of designers and artists, architects and fashion designers. Physically is unusual for athletes and dancers because these people are easier to learn in practice. Personal is also called emotional. $\mathrm{He}$ is responsible for what man says to him. Interpersonal people with this talent, mainly in the process of their activities, are closely related to society. These are politicians, salesmen, actors. The talent of the environment - this type of talent is more often endowed with trainers, farmers. This classification was proposed by the famous American psychologist Howard Gardner in the early 80s. Talent is a combination of abilities, their co mbination. That is, a single, isolated ability cannot be an analogue of talent, even if it has reached a very high level of development and is spoken. This is in particular confirmed by studies of people with a phenomenal memory. Meanwhile, he is in memory, his strength and capacity, many ready to see the equivalent of talent.

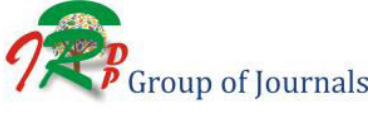




\subsection{The Relation and Difference of these Phenomena}

After analysing the problem of the relationship and the differences in abilities and talent, we can conclude that the opinion on this topic will be largely determined by the content that is put into these concepts. There is a real difficulty in defining concepts because it is related to a common understanding of these terms. If we turn to explanatory dictionaries, dictionaries of foreign words, we can see that very often the terms "capable", "gifted", "talented" are used as synonyms and refer to the degree of expressiveness of the abilities. It is also important to emphasize that the term "talented" defines a person's natural data. So, in the explanatory dictionary of W. Dahl, the "capable" is defined as "suitable for anything or inclined, modest, useful, controversial, suitable, opportunistic, convenient. Capable person is mentally gifted or developed; capable of mathematics, painting prone to this and understanding of it. "In fact, in this case, the skills are understood as qualified, but the concept of "skill" is not in the dictionary.

Therefore, the concept of "capable" is defined by the relationship of success to activity. In defining the concept of "talent", it is necess ary to build on its innate nature. That is, talent is an innate ability given by God that provides great success in human activity. In the dictionary of foreign words, talent is defined as "extraordinary natural abilities". Donation is regarded as a state of talent, as a degree of its seriousness. It is no coincidence that gifting, as a standalone concept, is absent in VI's explanatory dictionaries, Dahl, S. Ozegov and in the Explanatory Dictionary of Foreign Words. From the foregoing, we can conclude that abilities, talents, and talents are, however, separated on different grounds. When we talk about ability, we emphasize the ability of a person to do something and, by talking about talent, giftedness, we point to the innate nature of this person's quality (ability). At the same time, abilities, talents and talents are manifested in the success of the business. In my opinion, the concepts of ability, giftedness, and talent are similar in meaning, because if a person has them, they are closely related to each other.

This quality system is inherent, in my opinion, only to successful, purposeful people. If you start to study each of the criteria separately, you may catch a little noticeable line of difference. So, if the endowment is innate, one's genetically embedded qualities to show any abilities; that talent is the same qualities, but only with the difference that man has shown throughout his life.

\section{Conclusion}

The nature of human abilities causes quite heated debate among scientists. Are our abilities inborn or are they formed in vivo? Proponents of the idea of abilities claim that the abilities are biologically determined and their manifestation depends entirely on the inherited genetic background. Education and upbringing, according to scientists in this position can only speed up the process of manifestation of abilities, but even without pedagogical influence they will certainly emerge. Representatives of another extreme point of view believe that the characteristics of the psyche are determined by the quality of upbringing and training and that any person can develop any abilities.

Proponents of this trend refer to cases where the children of the most primitive tribes, having received appropriate training, were no different from educated Europeans. Here they also talk about the so-called "Mowgli children", who convincingly testify to irreparable damage, even the impossibility of human development outside of society. Abilities are formed and developed in the process of activity on the basis of makings - hereditary and innate psychological qualities of a person. Therefore, for the development of the ability to this type of activity, the indispensable implementation of this activity is necessary. Abilities characterize a person as a subject of activity. The problem of talent has been facing psychologists for a long time and today there is no single concept within the framework of any theory of personality that would explain it in full.

Most personality theories consider only a few aspects of this problem. Nevertheless, the study of the problems of the structure of talent is very important both for the theory of psychology and for the solution of specific psychological and pedagogical problems of modern education. When considering psychological literature, the question arises about the relationship between the concepts of ability, giftedness, and talent. In many sources, the concepts of giftedness and talent are interpreted as synonymous and are not shared. Genius is seen as the highest degree of manifestation of talent or giftedness. This implies the need to provide accurate concepts for the further disclosure of the problem: Abilities (ability) is individual psychological characteristics, defining success fulfillment activities or a number of activities irreducible to knowledge, skills, but determining the ease and speed of learning new ways and methods of activity. Talent (from the Greek talanton "weight, measure", then - "level of abilities) is identified by some psychologists as gifted, others are seen as a high level of development of abilities, especially special ones. There are general abilities associated with more general conditions of leading forms of human activity, and special with individual types of activity and general and special giftedness. The first correlates with the more general conditions of the leading forms of human activity, the second - with the requirements of its special types. From all the material we can conclude that these psychic qualities are called abilities, thanks to which man relatively easily

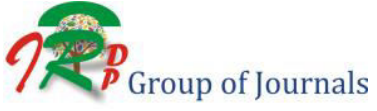


acquires knowledge, abilities and skills and success fully deals with any activity. But there are as many opinions and answers to this question as there are scientists who have considered the problem. These are well-known psychologists and educators: Doctor of Psychological Sciences N. Leits, Doctor of Pedagogical Sciences B.M. Teplov, A. Matushkin and many others.

\section{References}

[1] Schumpeter I, (1982), Economic Development Theory. M.,

[2] Angel J.F., Blackwell R.D., Miniard P.W., (1999), Consumer Behavior. SPb.

[3] Deineka O.S., (1991), Economic Psychology. SPb., Z. James W. Psychology.M.

[4] Ilyin E.P.,,(2000), Motivation and motives. SPb.

[5] Maslow A., (1993), The father reaches of human nature. Penguin (Non-Classics) p. 336.

[6] Maslow A., (1999), Motivation and Personality, St. Petersburg.

[7] Alekseev P.V., Panin A.V., (1991), Theory of knowledge and dialectics, $\mathrm{M}$.
[8] Alekseeva I. Yu., (1993), Human knowledge and its computer image, $M$.

[9] Ushakova D.V., (2000), Psychology of giftedness: from theory to practice, M.: PER SE.

[10] Kochergin A.N., (1990), Methods and forms of scientific knowledge, $\mathrm{M}$.

[11] Klimov E.A., (1969), Individual style of activity, Kazan..

[12] Leonhard K. (1997), Accentuated Personalities. Rostov-Don.

[13] Psychologist's Dictionary of Practice, (2001), Minsk, p. 506.

[14] Erickson E.,(1996), Identity: youth and crisis, M. - L.

[15] McClelland D., (2007), Human Motivation: Series "Masters of Psychology", St. Petersburg: Peter.

[16] Torrans E., (1965), Bringing creative thinking into, Education, Vol. 85., No.3, p. 547-550.

[17] Borland James H., (1991), Planning and Implementing Programs for the Gifted / James H. Borland. - New York, London Teachers college press, p.250.

[18] Angel J.F., Blackwell R.D., Miniard P.U., (1999) Consumer behavior. SPb.,p.331.

[19] Naumovski Ljupco and Jasminka Naumovska,"Uneployment and Unathorized Road about Apathy and Poverty the Macedonian Man without Knowledge and Skills" International Research Journal of Management, IT \& Social Sciences (IRJMIS) Vol. 4 Issue 4 July 2017 p. 39-50. 